\title{
Village Health Volunteers: Facing up to the Covid-19 Challenge
}

\section{Changsuphan $\mathrm{S}^{1 *}$ and Chaknum $\mathrm{P}^{2}$}

${ }^{1}$ Sukhothai Thammathirat Open University, School of Nursing, Thailand

${ }^{2}$ Faculty of Medicine Ramathibodi Hospital, Ramathibodi School of Nursing, Mahidol University, Thailand

*Corresponding author: Supattra Changsuphan, Lecturer in School of Nursing, Sukhothai Thammathirat Open University, Thailand, Email: supattra.map@stou.ac.th

\section{Mini Review}

Volume 4 Issue 2

Received Date: April 02, 2021

Published Date: April 07, 2021

DOI: $10.23880 /$ jqhe-16000216

\section{Abstract}

Village Health Volunteers (VHVs) are a crucial component of primary health care in Thailand. They have applied their role in collaboration with the nation's public health officials at primary and community hospitals since 1978 . The outbreak of the 2019 Coronavirus disease (COVID-19), first recorded in Wuhan, China at the end of 2019, has infected millions of people in almost every country in the world, leading to illness, hospitalization and, in many cases, untimely death. During this time global healthcare systems have been under enormous strain to contain the virus outbreak and treat sick people. COVID-19 first came to the attention of Thailand as a highly infectious disease on 26 February 2020, but the nation has successfully responded to the pandemic by focusing effort and resources on primary healthcare. VHVs have contributed significantly in their central role in preventing and controlling the virus in communities around the country.

Keywords: Village Health Volunteers (VHVs); Primary Health Care in Thailand; Public Health; Primary And Community Hospitals; Coronavirus 2019 (COVID-19)

\section{Introduction}

Since 1978, primary health care in Thailand has been implemented as the main strategy to improve public health by using Village Health Volunteers (VHVs) who live in their community and work as volunteers to care for residents within it [1]. VHVs support their communities in avoiding disease, and protect them from an epidemic not previously experienced.

Thailand declared Coronavirus Disease 2019 (COVID-19) as a dangerous and contagious disease under the Communicable Disease Act (2015) on February 26, 2020 - shortly after the pandemic had been officially identified by the Chinese government [2]. VHVs act in a significant way to prevent and control the pandemic [3].

\section{Village Health Volunteers (VHVS)}

According to the Ministry of Public Health curriculum, VHVs are selected from each village group or residence and receive appropriate training. They play an essential role as leaders of change in health behavior and providing health benefits.

Presently, there are approximately 1.04 million VHVs who conduct regular home visits, deliver medicines, provide healthcare education, and report to public health authorities. They are as important as doctors, nurses, and other public health officials because they have close access to vulnerable community areas.

During the COVID-19 outbreak, volunteers have played a crucial role in stopping the spread of the epidemic and other 
transmittable diseases in the community. As a consequence of the infectious nature of the contagion, VHVs must possess a self-defense mechanism, so it is vital that they prepare themselves before conducting home visits to observe COVID-19 symptoms [4].

\section{Volunteers' Preparation}

1. Follow the list of community-reported outbreaks tracked by the Department of Disease Control website, Ministry of Public Health [4].

2. Acquire a basic knowledge of COVID-19.

3. Know how to prevent COVID-19: Avoid the chances of contracting the disease by eating hot and fresh food, washing hands, wearing face masks, practicing social distancing, and exercising to keep fit.

4. Know the management mechanisms: Understand the surveillance mechanisms to prevent the spread of COVID-19 in community areas.

5. Coordinate preparation with community leaders: Conduct home visits that monitor people at risk of COVID-19 in their corresponding areas or community.

6. Observe self-health for home visits: Prevent members of the community from becoming disease carriers if they are suspected of having the virus.

7. Prepare protective equipment: Make available face masks and shields, surgical and cloth masks, biohazard bags, and alcohol gel.

\section{Volunteers' Role}

According to the Ministry of Public Health, the volunteers' role is to contribute their services by acting as their community's eyes and ears, and monitor the public health systems at the local level - an essential part of dealing with the COVID-19 virus [4-6]. Actions can be categorized into the following phases:

\section{- $\quad$ First Phase (Outbreak to February 2020)}

Volunteers organized a 'big cleaning week' environment with 1.3 million people participating in the activity. Selfprotection measures included eating hot and fresh foods, using personal spoons, wearing face masks, washing hands, practicing social distancing, and teaching villagers to make their own face masks from clothes during periods of short supply.

\section{- Second Phase (March 2 To 26, 2020)}

Set up an activity called: "Knocking on the Door of the Home against COVID-19," organized as a sub-district COVID-19 surveillance operation center, with the following guidelines [4]:

1. Volunteers knock on the door of a house in the community to educate, provide information, and advise people of their responsibilities (eat hot and fresh foods, use personal spoons, wash hands frequently, wear face masks, and exercise).

2. Screen at-risk groups and the general public.

3. Monitor and surveil the entire risk group and the general public for any abnormal symptoms, or monitor symptoms under supervision.

4. Report the performance of visits to residences by creating a list notifying vulnerable groups of public health workers in nearby areas.

\section{- Third Phase (From March 27, 2020)}

There is some relief to allow people to travel from Bangkok and its suburbs to other provinces under urgent surveillance and control of disease outbreaks. The event was called:

"Volunteer Knocking on the Door of the Home against COVID-19: Finding to Finish in 14 Days"

A volunteer is assigned from the COVID-19 volunteer team at district or community level to find vulnerable groups traveling within the community, and follow up to observe any symptoms in risk groups at their residence (14-day quarantine period).

\section{Operation Results}

Volunteers have knocked on community doors and searched and screened 14,074,193 vulnerable people in groups of houses who were found at risk, even though they had come from abroad or from Bangkok and its vicinities. Around 1,035,203 people close to, or exposed to, risk groups, and 1,016,711 people close to risk groups at home (home quarantine) were offered innovative care methods, consistent with the COVID-19 situation [7].

VHVs deliver drugs to patients with chronic conditions, take blood pressure measurements, and draw blood from diabetic patients for home-setting social measures. For example, VHVs set up a temperature screening checkpoint before people enter a village or community to promote social distancing in all community activities [8]. Between March 27 and April 11, VHVs visited 8 million additional households to support case-finding efforts.

\section{Fourth Phase}

Implement measures to relieve volunteers with behavioral changes based on a new way of life ('New Normal') and co-create measures to maintain social distancing. Guidelines and roles for volunteers have been established to create a new way of community life. 


\section{Fifth Phase (From January 27, 2020)}

The MOU (Memorandum of Understanding) of vaccination planning has played an important role in communication. Knowledge and information have been published about COVID-19 vaccination to the community in charge, called: "The VHVs know and tell about the safety of COVID-19".

\section{Conclusion}

The Village Health Volunteers (VHVs) program has been significant in stopping the spread of COVID- 19 in Thailand, especially at the community level. It is the primary level of defense before a more considerable degree of preventive measures against the virus.

Results have confirmed a shallow infection rate, combined with disease prevention and control systems, screening findings, early detection, early treatment, and limiting epidemic circles. However, the crucial role played by the VHVs program should be further assessed in order to respond to future challenges.

\section{References}

1. Primary Health Care Division (2015) Evolution of primary health care in Thailand (1978-2014). Primary Health Care Division, The War Veterans Organization of Thailand, Bangkok, Thailand pp: 23-45.
2. Ministry of Public Health (2020) Public health practice guidelines for the management of the COVID-19 epidemic in the provisions of Article 9 of the Emergency Decree on Public Administration in Emergencies, B.E. 2548 (No.1). Ministry of Public Health, Nonthaburi, Thailand.

3. Tejativaddhana P, Suriyawongpaisal W, Kasemsup V, Suksaroj T (2020) The roles of village health volunteers: COVID-19 prevention and control in Thailand. ACHSM 15(3): 18-22.

4. Thai Health Promotion Foundation (2021) A guidebook for volunteers to knock on the door to homes visit for COVID-19's symptoms observe. Thai Health Promotion Foundation, Bangkok, Thailand.

5. Pawungkarat S, Argchanasuk S, Nanchu P (2020) A Study of COVID-19 Surveillance, Prevention and Control in Communities towards Village Health Volunteers. Primary Health Care Division, Thailand.

6. Department of Health Service Support (2021) Practice guidelines, volunteers. Knocking on the door. Primary Health Care Division, Thailand.

7. WHO Thailand's (2020) Coronavirus disease 2019 (COVID-19): Thailand situation. World Health Organization, Thailand.

8. Department of Health Service Support (2021) Village Health Volunteers know and tell safety from COVID-19. In: Health MoP -that is, general public. 